\title{
Conflicting Reports Regarding the
}

\section{Histopathological Features of Androgenic} Alopecia: Are Biopsy Location, Hair Diameter Diversity, and Relative Hair Follicle Miniaturization Partly to Blame?

\section{Robert English Jnr (D) \\ Sophia Ruiz (D)}

Perfect Hair Health, San Francisco, CA 94115 , USA
Correspondence: Robert English Jnr Perfect Hair Health, 202 I Fillmore Ste \# 98, San Francisco, CA, 94115, USA Email Rob@perfecthairhealth.com
This article was published in the following Dove Press journal: Clinical, Cosmetic and Investigational Dermatology

\begin{abstract}
Despite decades of study, debate persists over the role of inflammation, fibrosis, and prostaglandins in the histopathology of androgenic alopecia (AGA). This brief review proposes that inconsistent findings across histological studies are a consequence of three inadequately controlled variables: 1) biopsy location, 2) hair diameter diversity (HDD), and 3) relative hair follicle miniaturization (HFM) within and across subjects. We suggest new methodological considerations to improve AGA histopathological research, as well as a novel classification system to quantify HFM by its stages. Finally, we hypothesize a dynamic relationship between inflammation, fibrosis, and prostaglandin activity dependent on relative HFM.
\end{abstract}

Keywords: androgenic alopecia, hair diameter diversity, inflammation, fibrosis, prostaglandins

\section{Introduction}

AGA is a progressive hair loss disorder that predominantly affects skin tissues above the galea aponeurotica. It is well-established that AGA is mediated by androgens and genetics. ${ }^{1}$ However, there is less consensus surrounding its histopathology - particularly in regard to the presence of inflammation, fibrosis, and prostaglandin activity in balding tissues.

In his landmark study, Whiting discovered inflammation and/or fibrosis in $70 \%$ of AGA-affected biopsied vertices compared to $40.9 \%$ of non-balding controls. ${ }^{2}$ These findings were corroborated in a follow-up investigation demonstrating inflammation and/or fibrosis in $71.4 \%$ versus $37 \%$ of balding and non-balding controls, respectively. ${ }^{3}$ Since then, histological studies have built on and conflicted with Whiting's work (Table 1). ${ }^{4-15}$ For instance, Goyal et al found no evidence of inflammation or fibrosis in men with moderate AGA. ${ }^{14}$ El-Domyati et al found that the magnitude of fibrosis increased alongside Norwood gradients - with follicular destruction observed in AGA's advanced stages. ${ }^{11}$ Recently, Valdebran et al noted fibrosis in $68 \%$ of AGA biopsies and $82 \%$ of non-balding controls - calling into question the role of inflammation and fibrosis in AGA. ${ }^{15}$ 


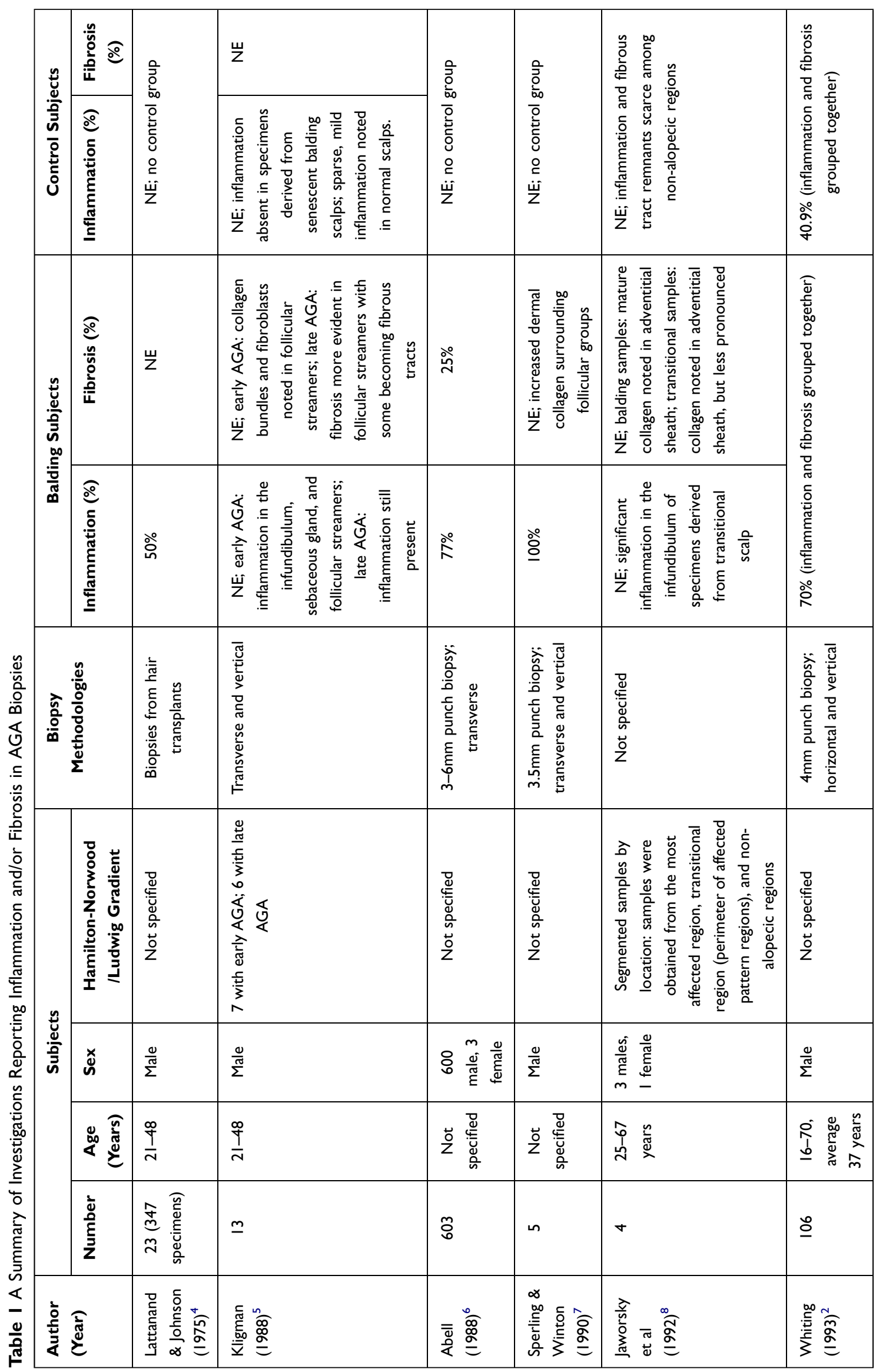




\begin{tabular}{|c|c|c|c|}
\hline 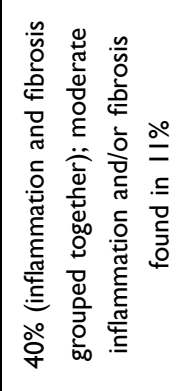 & 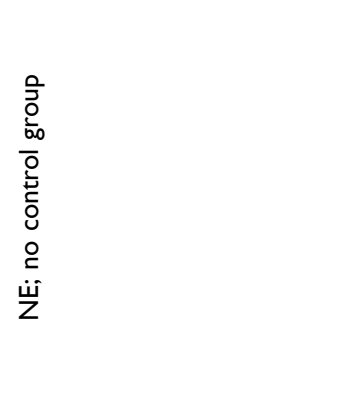 & 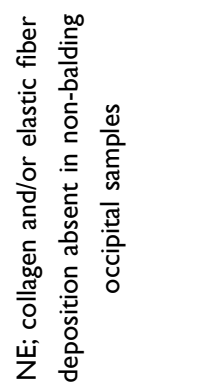 & 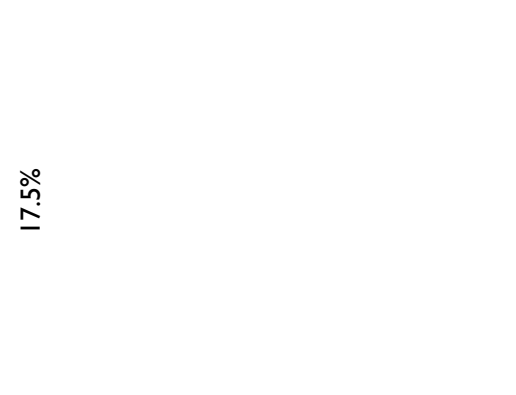 \\
\hline \multirow{2}{*}{ 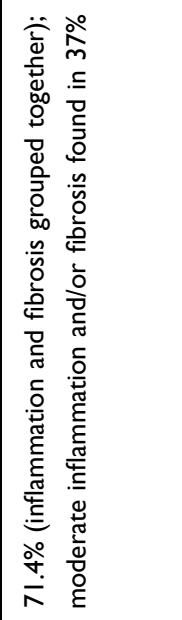 } & 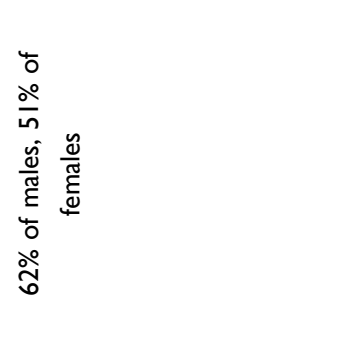 & 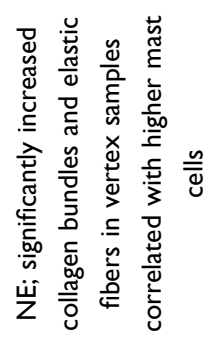 & 亏े \\
\hline & 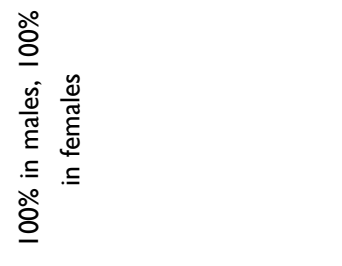 & 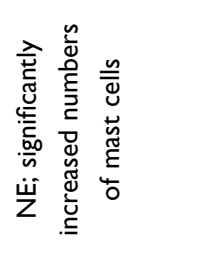 & ڤั \\
\hline 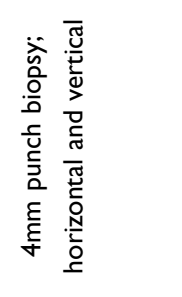 & 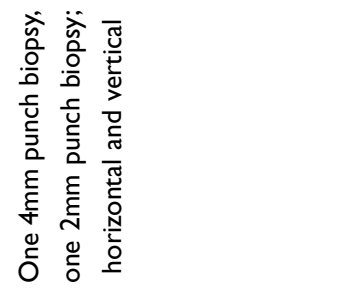 & 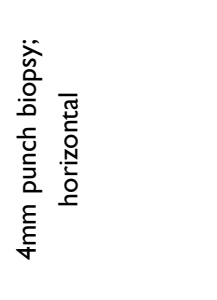 & 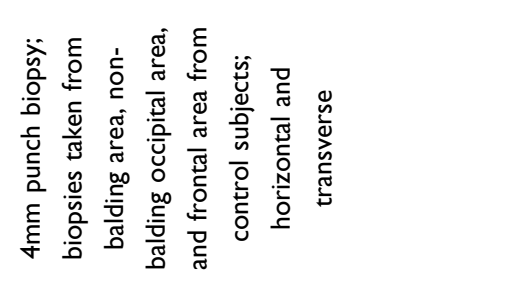 \\
\hline 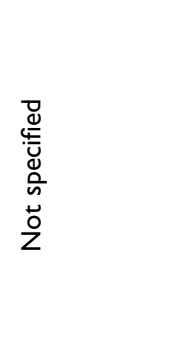 & 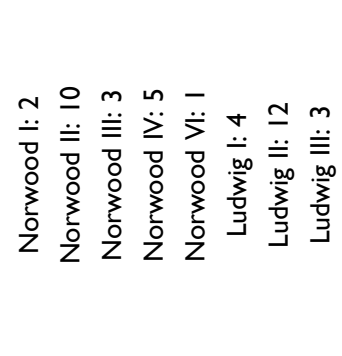 & 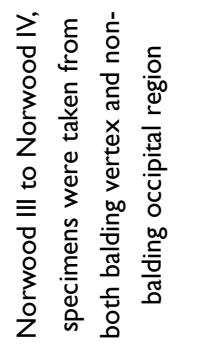 & 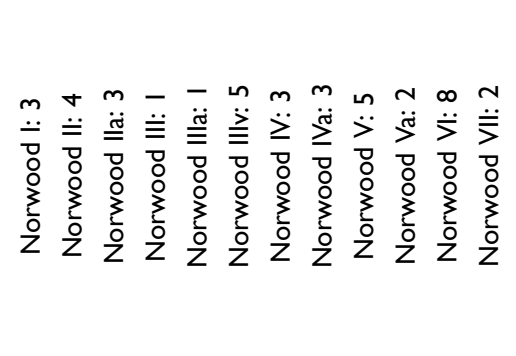 \\
\hline 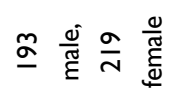 & 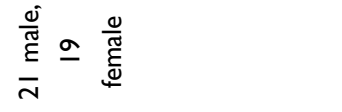 & $\frac{\frac{0}{\pi}}{\Sigma}$ & $\frac{\frac{\omega}{\pi}}{\Sigma}$ \\
\hline 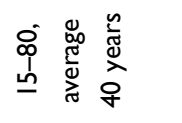 & 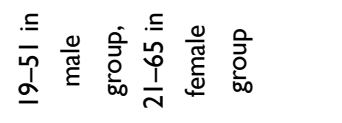 & 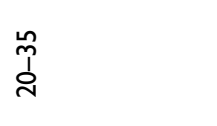 & $\begin{array}{l}\infty \\
0 \\
1 \\
\text { i }\end{array}$ \\
\hline$\frac{\mathfrak{d}}{\mathfrak{d}}$ & 우 & 으 & 우 \\
\hline 总 & 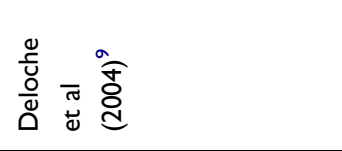 & 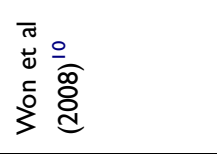 & 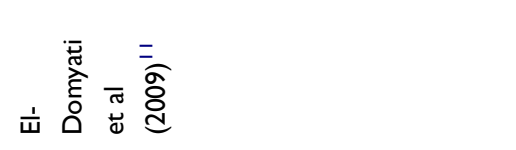 \\
\hline
\end{tabular}




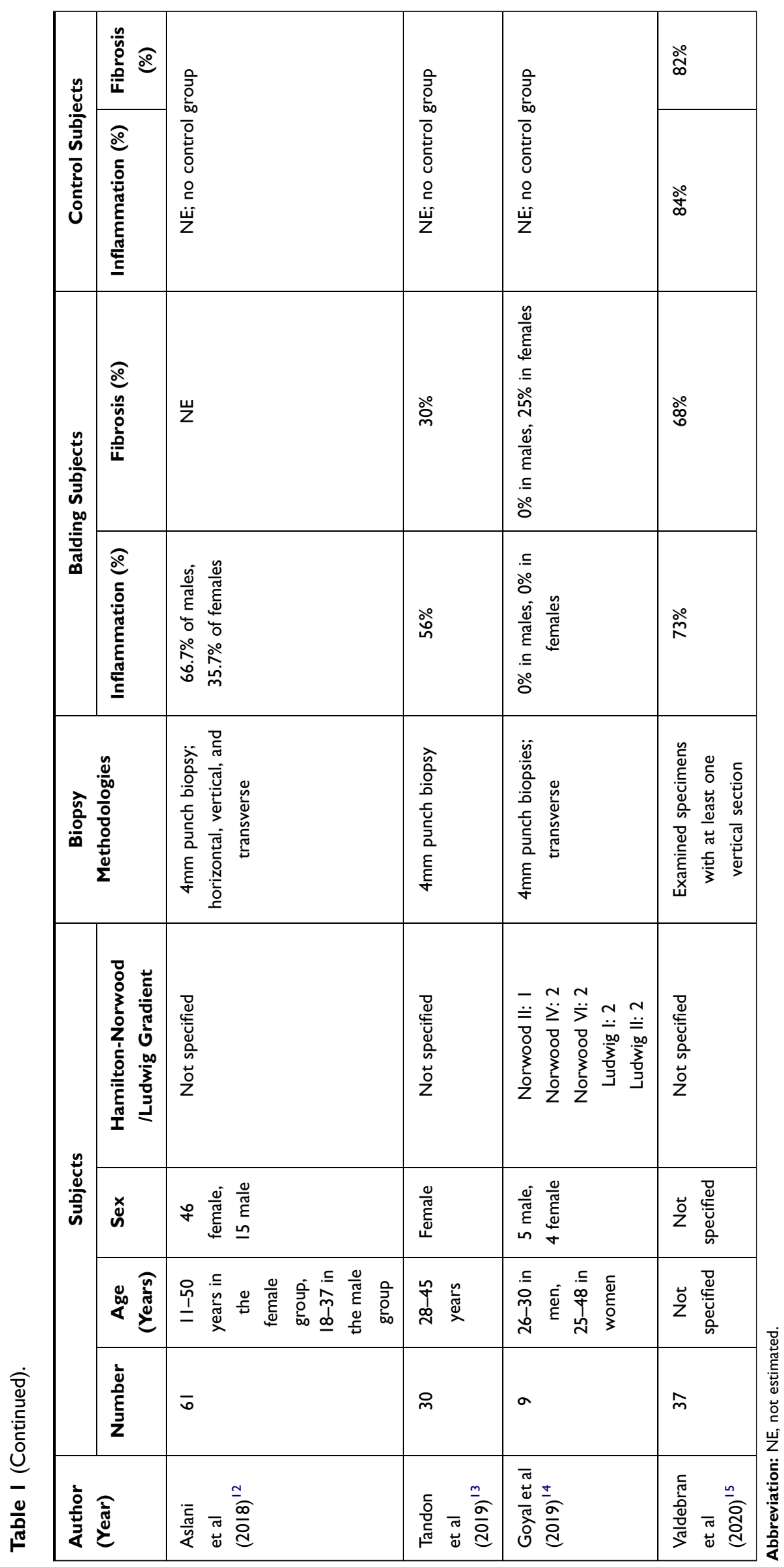


Conflicting histological reports have also emerged regarding prostaglandin activity in balding scalps. In 2012, Garza et al found that prostaglandin $\mathrm{D}_{2}\left(\mathrm{PGD}_{2}\right)$ and prostaglandin $\mathrm{J}_{2}\left(\mathrm{PGJ}_{2}\right)$ levels were elevated in balding scalps, and that prostaglandin $\mathrm{E}_{2}\left(\mathrm{PGE}_{2}\right)$ levels were higher in non-balding scalps. ${ }^{16}$ However, follow-up investigations by Villarreal-Villarreal et al found no significant differences in $\mathrm{PGD}_{2}$ levels across balding and non-balding subjects, and concluded that $\mathrm{PGE}_{2}$ synthase was only elevated in biopsies of early-stage AGA subjects. ${ }^{17}$ Most recently, Chovarda et al found higher $\mathrm{PGD}_{2}$ and $\mathrm{PGI}_{2}$ and lower $\mathrm{PGE}_{2}$ and $\mathrm{PGF}_{2 \mathrm{a}}$ in balding scalps - further elucidating a complex relationship between prostaglandins and AGA. ${ }^{18}$

Some authors suggest that inconsistent histological findings are due to differences across study subject demographics (ie, age, sex, and/or race) and methodologies (ie, transverse versus horizontal biopsies and/or the use of demographic-matched, non-balding controls). ${ }^{19,20}$ These are plausible considerations. Nonetheless, three additional variables may greatly influence study outcomes, none of which are adequately controlled for in histological investigations: biopsy location, HDD, and relative HFM.

We propose the hypothesis that biopsy location, HDD, and relative HFM are responsible for the majority of conflicting findings across AGA histological studies. We introduce a classification system to quantify relative HFM and control for these variables. Finally, we hypothesize a dynamic relationship between inflammation, fibrosis, and prostaglandin activity in AGA that attempts to make sense of conflicting histopathological reports: a model dependent on relative HFM.

\section{Discussion}

\section{Histopathological Challenges}

AGA progresses through reductions in hair diameter, also known as HFM. ${ }^{21}$ HFM is considered a single stepprocess; it is believed to occur during reentry into anagen and worsen with each subsequent hair cycle. ${ }^{21}$ In AGA, hair cycling rates are not uniform. As such, AGA-affected locations often present with hair diameters ranging from full-thickness to miniaturized to vellus - even within $1 \mathrm{~mm}$ zones. This phenomenon is termed anisotrichosis, also known as HDD. ${ }^{22}$ When terminal HDD varies by more than $20 \%$, it is used as a diagnostic tool for $\mathrm{AGA}^{23}$ In all likelihood, HDD of less than $20 \%$ may also indicate earlystage AGA, albeit at cosmetically imperceptible levels. ${ }^{24}$
HDD is ubiquitous but variable across AGA locations, gradients, and subjects. ${ }^{23}$ As such, its presence poses a unique challenge in histopathological research. Current understandings of AGA histology come from analyses of $2-4 \mathrm{~mm}$ punch biopsies. Biopsies are conducted on subjects with cosmetic AGA - often at gradients of Norwood 2-4. Due to concerns of scarring, investigators often biopsy regions where incisions are less conspicuous, like the vertex (Table 1).

Under these circumstances, a $4 \mathrm{~mm}$ vertex biopsy may contain anywhere from 10 to 50 hairs $-80 \%$ of which are terminal. ${ }^{2}$ However, within each biopsy, terminal HDD varies: some terminal hairs appear unaffected by HFM, while others appear toward the final stages of HFM. Resultantly, $1 \mathrm{~mm}$ adjustments to biopsy location can skew HDD and HFM toward earlier or later miniaturization cycles (Figure 1). As such, HDD and relative HFM are phenomena that reduce the usefulness of standardizing biopsies based only on subject demographics, general location (ie, vertex), and Norwood gradient - particularly if research objectives involve elucidating histological changes throughout AGA's multi-stage progression.

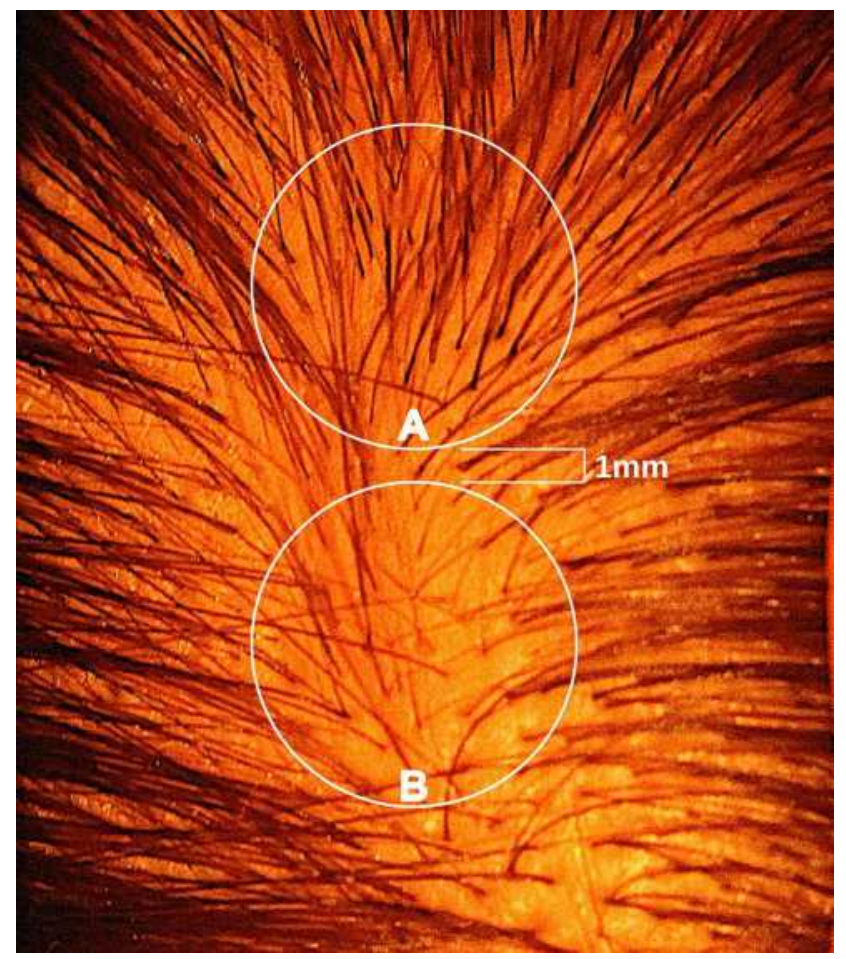

Figure I A photograph of a male vertex in the early stages of AGA. Zones represent potential biopsy locations separated by approximately I $\mathrm{mm}$. Zone A features relatively high hair counts, low HDD, and terminal hair follicles skewed toward earlier cycles of HFM. Zone B features relatively low hair counts, high HDD, and terminal hair follicles skewed toward later cycles of HFM.

Abbreviations: AGA, androgenic alopecia; HDD, hair diameter diversity; HFM, hair follicle miniaturization. 


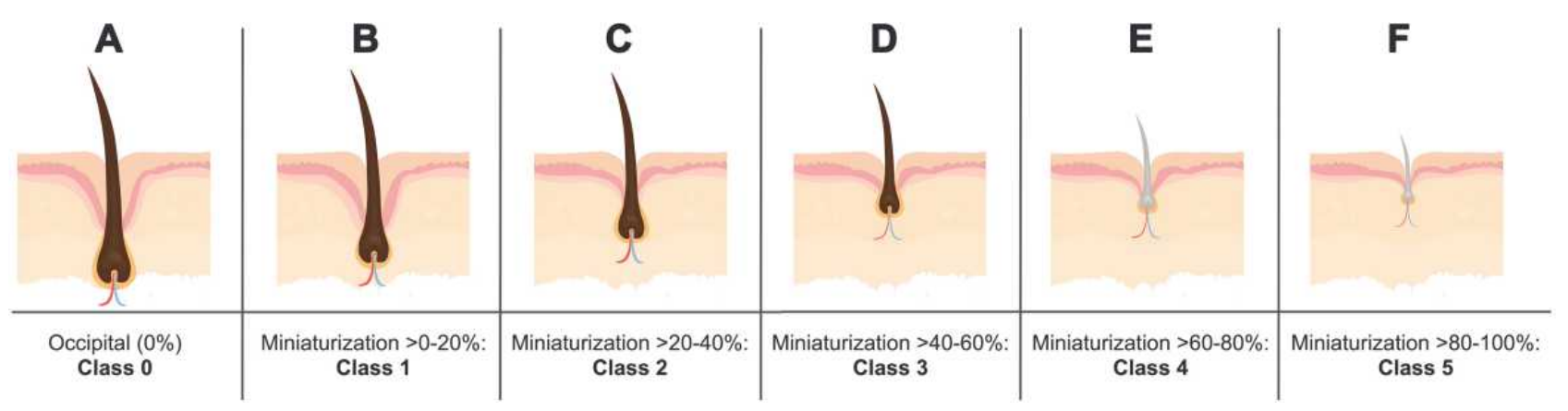

Figure 2 A proposed classification system to quantify relative HFM within the same subject. (A) Class 0 represents full-thickness hairs unaffected by AGA. (B-F) Classes I-5 represent AGA-affected hairs benchmarked to Class 0 , with miniaturization segmented by $20 \%$ increments per class.

Abbreviations: HFM, hair follicle miniaturization; AGA, androgenic alopecia.

Dermatopathologists stress the importance of performing biopsies at the edge of disease onset to capture both affected and unaffected tissue. ${ }^{25}$ However, AGA's slow and widespread progression often obfuscates an early diagnosis due to change blindness. Therefore, by the time AGA becomes a cosmetic concern, HDD is already greater than $20 \%$, HFM has already occurred over several hair cycles, and its initial edge of onset is difficult to discern. Therefore, as investigators continue to preferentially select for AGA subjects with visual hair loss, histological research continues to underrepresent AGA in its earliest of stages (Table 1).

Lastly, in private conversations with dermatologists, trichoscopic examinations tend to show some degree of HDD in nearly all post-pubertal patients. If true, this suggests that the incidence of AGA is higher than previously reported, that $\mathrm{AGA}$ initiates much earlier than it cosmetically presents, and that inflammation in nonbalding controls may actually indicate early-stage AGA albeit with HDD of less than $20 \%$. This draws into question the utility of comparing biopsies of balding scalps to location- and demographic-matched non-balding controls at least without intrasubject evaluations to measure hair diameter in balding-prone versus donor-safe scalp regions.

\section{Methodological Considerations}

It is imperative that future histopathological AGA investigations not only control for Norwood gradient and biopsy location, but also HDD and relative HFM within and across subjects. Without accounting for HDD and relative HFM, conflicting reports regarding the presence of inflammation, fibrosis, and prostaglandins in AGA are likely to persist.

Historically, HDD is used as a binary measurement: it is present if an arbitrary examination zone shows hair diameter variations greater than $20 \%$. Measuring HDD is simple; however, its usefulness in histological research is limited without also capturing relative HFM. For example, HDD is often undetectable in biopsies of early- and late-stage AGA where hair diameters present uniformly as near-full thickness or near-completely miniaturized, respectively. Therefore, in addition to HDD, we propose that research teams also control for relative HFM within balding and non-balding controls.

Relative HFM can be established for each subject by averaging terminal hair diameters in a biopsied region, $D_{\text {biopsy }}$, to compare against average terminal diameters in a donor-safe region, $D_{\text {donor }}$. Preferably, donor-safe hairs would be measured in occipital zones A1, B1, and C1, where Yun et al found the widest hair diameters. ${ }^{24}$

$$
\left(1-\frac{D_{\text {biopsy }}}{D_{\text {donor }}}\right) \cdot 100 \%=\text { Relative HFM }
$$

Finally, relative HFM can be segmented by $20 \%$ increments and denoted by five classes to distinguish magnitudes of miniaturization (Figure 2). In adult male scalps, the average diameter of terminal hair versus AGA-affected vellus hair ranges from 70 to $90 \mu \mathrm{m}$ and 25 to $35 \mu \mathrm{m}$, respectively. ${ }^{24,26,27}$ Thus, a five-stage classification system would allow for histological observations across three stages of terminal HFM (Figure 2B and C) and two stages of vellus HFM (Figure $2 \mathrm{E}$ and $\mathrm{F}$ ) in relation to a hair follicle unaffected by AGA (Figure 2A).

Altogether, controlling for HDD and relative HFM would serve to (1) identify balding subjects inadvertently featured as non-balding controls, and (2) clarify the histological role of inflammation, fibrosis, and prostaglandin activity across all classes of HFM, and thereby multiple stages of AGA.

\section{Hypothetical Model}

Conflicting histological reports regarding inflammation and fibrosis have stirred debate over whether AGA should be considered a scarring or nonscarring alopecia - with many 


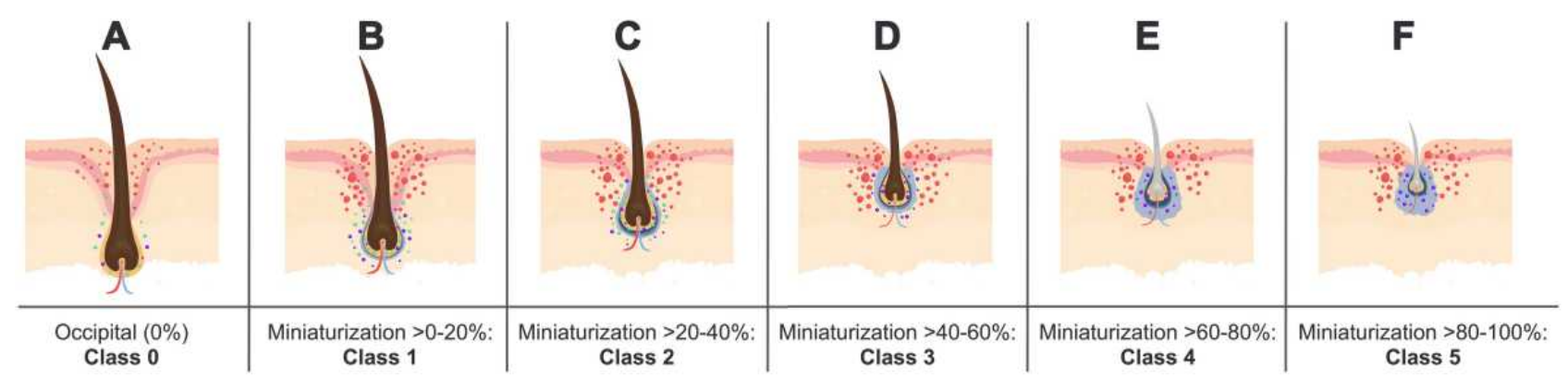

Figure 3 A hypothetical model showing a dynamic relationship between AGA and the presence of inflammation, fibrosis, and prostaglandin activity based on relative HFM. Inflammation is denoted by red markings; $P E_{2}$ synthase is denoted by green markings; $P_{G^{\prime}} D_{2}$ and $P G J_{2}$ are denoted by purple markings; fibrosis is denoted by blue perifollicular shading. (A) Class 0 hair follicles unaffected by $A G A$ show no fibrosis and relatively low levels of inflammation, $P G E_{2}$ synthase, $P G D_{2}$, and $P G J_{2}$. (B and $\mathbf{C}$ ): $C_{1}$ lass I-2 hair follicles in the early stages of HFM show relatively low levels of fibrosis but increased inflammation, $P E_{2}$ synthase, $P G D_{2}$, and PG ${ }_{2}$. (D-F) Class $3-5$ hair follicles in the mid- to late-stages of HFM show increasing levels of fibrosis, decreased activity of $P_{G} E_{2}$ synthase, and sustained levels of $P G D_{2}$ and $P G J_{2}$.

Abbreviations: $A G A$, androgenic alopecia; HFM, hair follicle miniaturization; $\mathrm{PGE}_{2}$, Prostaglandin $\mathrm{E}_{2} ; \mathrm{PGD}_{2}, \operatorname{Prostaglandin}_{\mathrm{D}_{2}}$; $P \mathrm{~J}_{2}$, Prostaglandin $\mathrm{J}_{2}$.

investigators settling on a biphasic definition. ${ }^{28}$ Inconsistent findings regarding prostaglandin activity have led VillarrealVillarreal et al to suggest that $\mathrm{PGE}_{2}$ synthase is upregulated in the early stages of AGA in order to protect hair follicles from miniaturization. ${ }^{17}$ Taking these stances into consideration, we hypothesize a dynamic relationship between AGA and the presence of inflammation, fibrosis, and prostaglandins dependent on relative HFM (Figure 3).

In the absence of HFM, our model suggests that hair follicles show no fibrosis and relatively low levels of inflammation, $\mathrm{PGE}_{2}$ synthase, $\mathrm{PGD}_{2}$, and $\mathrm{PGJ}_{2}$ (Figure $3 \mathrm{~A}$ ). During early stages of HFM (ie, hair diameter reductions greater than $0 \%$ and up to $40 \%$ ), hair follicles show relatively low levels of fibrosis but increased inflammation, $\mathrm{PGE}_{2}$ synthase, $\mathrm{PGD}_{2}$, and $\mathrm{PGJ}_{2}$ (Figure $3 \mathrm{~B}$ and $\mathrm{C}$ ). During mid- to late-stages of HFM (ie, hair diameter reductions greater than $40 \%$ ), hair follicles show increasing levels of fibrosis, decreased activity of $\mathrm{PGE}_{2}$ synthase, and sustained levels of $\mathrm{PGD}_{2}$ and $\mathrm{PGJ}_{2}$ (Figure 3D-F). This hypothetical model would help make sense of decades worth of conflicting histological reports without undermining or dismissing any past findings.

\section{Testing the Hypothesis}

Testing our hypothesis would require, for each participant, the collection of five datapoints from both affected and unaffected AGA scalp regions: hair counts, hair diameters, and histological assessments of inflammation, fibrosis, and prostaglandin activity. Hair counts and hair diameters could be established non-invasively through dermoscopy and image analysis software. However, to the best of our knowledge, determining the presence and magnitude of inflammation, fibrosis, and prostaglandin activity in scalp skin would require a biopsy. This poses a methodological challenge: most AGA patients are not diagnosed through biopsies, nor are they eager to undergo invasive procedures that potentiate scarring. Thus, to improve the testability of our hypothesis, there is a need to develop non-invasive methods to measure inflammation, fibrosis, and prostaglandins in cutaneous tissues.

There are non-invasive devices to assess inflammatory, proliferative, and remodeling phases of wound-healing in vivo for cutaneous tissues. ${ }^{29}$ Some of these technologies may soon evolve to support hair loss research. Recently, Mogensen et al demonstrated that optical coherence tomography - in combination with topical gold nanoshells enhanced the contrast of hair follicles and allowed for in vivo histological analysis at a resolution of 2 to $6 \mu \mathrm{m}$, but only to a depth of $1.2 \mathrm{~mm} .{ }^{30}$ Çildağ and Çildağ found that sonoelastography could assess the magnitude of skin fibrosis in subjects with diffuse cutaneous systemic sclerosis, albeit with lower accuracy in early stages of disease development. ${ }^{31}$ Laistler et al found that magnetic resonance imaging alongside highly-sensitive superconducting surface coils could achieve in vivo skin images that distinguished cutaneous layers and blood vessel walls, but only up to a resolution of $80 \mu \mathrm{m} .{ }^{32}$ Interestingly, magnetic resonance imaging has demonstrated utility in diagnosing AGA, determining hair follicle depth, and measuring epidermal, dermal, and hypodermal layer thickness. ${ }^{33}$ Finally, Mize et al found that non-invasive reverse iontophoresis could measure, in vivo, changes to cutaneous $\mathrm{PGE}_{2}$ from drug-induced irritation, but not from agents that induced vasodilation or vasoconstriction. ${ }^{34}$ With continued advancements, optical coherence tomography, sonoelastography, magnetic resonance imaging, and reverse iontophoresis may allow for realtime in vivo monitoring of inflammation, fibrosis, and 
prostaglandins in AGA - thereby accelerating histopathological research across a variety of hair loss disorders.

\section{Conclusion}

In AGA, the ubiquitous but variable presence of HDD and relative HFM undermine the utility of controlling histological investigations only for subject demographics and biopsy locations. We hypothesize that biopsy location, HDD, and relative HFM are responsible for the majority of conflicting findings across AGA histopathological investigations - and that a dynamic relationship exists between inflammation, fibrosis, and prostaglandins dependent upon relative HFM. We propose methodological considerations to account for HDD and relative HFM, as well as a novel classification system to establish relative HFM within each subject. Controlling for HDD and relative HFM can be accomplished by (1) measuring hair diameters within a biopsy to establish HDD, and (2) comparing biopsied hair diameters to those found in regions protected from AGA (ie, the occipital) to establish relative HFM. Such methodologies would not significantly complicate any investigation. They might, however, clarify decades worth of conflicting reports regarding AGA's histopathology.

\section{Author Contributions}

All authors made substantial contributions to conception and design, acquisition of data, or analysis and interpretation of data; took part in drafting the article or revising it critically for important intellectual content; agreed to submit to the current journal; gave final approval of the version to be published; and agree to be accountable for all aspects of the work.

\section{Disclosure}

Robert English and Sophia Ruiz have no conflicts to declare.

\section{References}

1. Cash T. The psychosocial consequences of androgenetic alopecia. Rev Res Lit. 1999;141:398-405.

2. Whiting DA. Diagnostic and predictive value of horizontal sections of scalp biopsy specimens in male pattern androgenetic alopecia. $J \mathrm{Am}$ Acad Dermatol. 1993;28(5 Pt 1):755-763. doi:10.1016/0190-9622(93) 70106-4

3. Whiting DA. Chronic telogen effluvium: increased scalp hair shedding in middle-aged women. J Am Acad Dermatol. 1996;35(6):899-906.

4. Lattanand A, Johnson WC. Male pattern alopecia a histopathologic and histochemical study. $J$ Cutan Pathol. 1975;2(2):58-70. doi:10.1111/j.1600-0560.1975.tb00209.x

5. Kligman AM. The comparative histopathology of male-pattern baldness and senescent baldness. Clin Dermatol. 1988;6(4):108-118. doi:10.1016/0738-081x(88)90074-0
6. Abell E. Histologic response to topically applied minoxidil in male-pattern alopecia. Clin Dermatol. 1988;6(4):191-194. doi:10.1016/0738-081x(88)90086-7

7. Sperling LC, Winton GB. The transverse anatomy of androgenic alopecia. $J$ Dermatol Surg Oncol. 1990;16(12):1127-1133. doi:10.1111/j.1524-4725.1990.tb00024.x

8. Jaworsky C, Kligman AM, Murphy GF. Characterization of inflammatory infiltrates in male pattern alopecia: implications for pathogenesis. Br J Dermatol. 1992;127(3):239-246. doi:10.1111/ j.1365-2133.1992.tb00121.x

9. Deloche C, de Lacharriere O, Misciali C, et al. Histological features of peripilar signs associated with androgenetic alopecia. Arch Dermatol Res. 2004;295(10):422-428. doi:10.1007/s00403-003$0447-\mathrm{y}$

10. Won $\mathrm{CH}$, Kwon OS, Kim YK, et al. Dermal fibrosis in male pattern hair loss: a suggestive implication of mast cells. Arch Dermatol Res. 2008;300(3):147-152. doi:10.1007/s00403-007-0826-x

11. El-Domyati M, Attia S, Saleh F, Abdel-Wahab H. Androgenetic alopecia in males: a histopathological and ultrastructural study. $J$ Cosmet Dermatol. 2009;8(2):83-91. doi:10.1111/j.14732165.2009.00439.x

12. Sari Aslani F, Heidari Esfahani M, Sepaskhah M. Non-scarring Alopecias in Iranian Patients: a Histopathological Study With Hair Counts. Iran J Pathol Summer. 2018;13(3):317-324.

13. Tandon S, Arora P, Gautam RK, Bhardwaj M, Garga U, Sharma N. Correlation between clinical features, biochemical parameters, and histopathological findings in women with patterned baldness: a study from North India. J Cutan Aesthet Surg. 2019;12(1):42-48. doi:10.4103/JCAS.JCAS_30_18

14. Goyal M, Khandpur S, Ramam M, Sharma VK, Singh MKA. Study of the histopathological features of alopecias on transverse sections of scalp biopsies. Indian J Dermatol. 2019;64(1):47-54. doi:10.4103/ ijd.IJD_477_17

15. Valdebran M, Mo J, Elston DM, Doan L. Pattern hair loss: assessment of inflammation and fibrosis on histologic sections. $\mathrm{J} \mathrm{Am}$ Acad Dermatol. 2020;82(3):757-758. doi:10.1016/j.jaad.2019.0 9.013

16. Garza LA, Liu Y, Yang Z, et al. Prostaglandin D2 inhibits hair growth and is elevated in bald scalp of men with androgenetic alopecia. Sci Transl Med. 2012;4(126):126ra34. doi:10.1126/ scitranslmed.3003122

17. Villarreal-Villarreal CD, Sinclair RD, Martinez-Jacobo L, et al. Prostaglandins in androgenetic alopecia in 12 men and four female. J Eur Acad Dermatol Venereol. 2019;33(5):e214-e215. doi:10.1111/ jdv. 15479

18. Chovarda E, Sotiriou E, Lazaridou E, Vakirlis E, Ioannides D. The role of prostaglandins in androgenetic alopecia. Int J Dermatol. 2021. doi:10.1111/ijd.15378

19. Sadick N, Magro C. Response to Letter to the Editor. J Am Acad Dermatol. 2020. doi:10.1016/j.jaad.2020.04.176

20. Valdebran M, Doan L, Elston DM. Reply to comment on: pattern hair loss. Assessment of inflammation and fibrosis on histologic sections. J Am Acad Dermatol. 2020. doi:10.1016/j.jaad.2020.05.040

21. Krajcik RA, Vogelman JH, Malloy VL, Orentreich N. Transplants from balding and hairy androgenetic alopecia scalp regrow hair comparably well on immunodeficient mice. $J$ Am Acad Dermatol. 2003;48(5):752-759. doi:10.1067/mjd.2003.95

22. Sewell LD, Elston DM, Dorion RP. "Anisotrichosis": a novel term to describe pattern alopecia. J Am Acad Dermatol. 2007;56(5):856. doi:10.1016/j.jaad.2007.01.020

23. de Lacharriere O, Deloche C, Misciali C, et al. Hair diameter diversity: a clinical sign reflecting the follicle miniaturization. Arch Dermatol. 2001;137(5):641-646.

24. Yun SS, Park JH, Na YC. Hair diameter variation in different vertical regions of the occipital safe donor area. Arch Plast Surg. 2017;44 (4):332-336. doi:10.5999/aps.2017.44.4.332 
25. Vidal CI. Overview of Alopecia: a Dermatopathologist's Perspective. Mo Med. 2015;112(4):308-312.

26. Leerunyakul K, Suchonwanit P. Evaluation of hair density and hair diameter in the adult thai population using quantitative trichoscopic analysis. Biomed Res Int. 2020;2020:2476890. doi:10.1155/2020/2476890

27. Lee MS, Kossard S, Wilkinson B, Doyle JA. Quantification of hair follicle parameters using computer image analysis: a comparison of androgenetic alopecia with normal scalp biopsies. Australas J Dermatol. 1995;36 (3):143-147. doi:10.1111/j.1440-0960.1995.tb00956.x

28. Stefanato CM. Histopathology of alopecia: a clinicopathological approach to diagnosis. Histopathology. 2010;56(1):24-38. doi:10.1111/j.1365-2559.2009.03439.x

29. Ud-Din S, Bayat A. Non-invasive objective devices for monitoring the inflammatory, proliferative and remodelling phases of cutaneous wound healing and skin scarring. Exp Dermatol. 2016;25 (8):579-585. doi:10.1111/exd.13027

30. Mogensen M, Bojesen S, Israelsen NM, et al. Two optical coherence tomography systems detect topical gold nanoshells in hair follicles, sweat ducts and measure epidermis. J Biophotonics. 2018;11(9): e201700348. doi:10.1002/jbio.201700348
31. Cildag S, Cildag MB. The relationship between the degree of skin fibrosis by sonoelastography and the degree of pulmonary involvement in scleroderma. Turk J Med Sci. 2017;47(5):1555-1559. doi:10.3906/sag-1702-44

32. Laistler E, Poirier-Quinot M, Lambert SA, et al. In vivo MR imaging of the human skin at subnanoliter resolution using a superconducting surface coil at 1.5 Tesla. J Magn Reson Imaging. 2015;41 (2):496-504. doi:10.1002/jmri.24549

33. Soga S, Koyama T, Mikoshi A, et al. Quantitative analysis of the anatomical changes in the scalp and hair follicles in androgenetic alopecia using magnetic resonance imaging. Skin Res Technol. 2021;27(1):56-61. doi:10.1111/srt.12908

34. Mize NK, Buttery M, Daddona P, Morales C, Cormier M. Reverse iontophoresis: monitoring prostaglandin E2 associated with cutaneous inflammation in vivo. Exp Dermatol. 1997;6(6):298-302. doi:10.1111/j.1600-0625.1997.tb00176.x

\section{Publish your work in this journal}

Clinical, Cosmetic and Investigational Dermatology is an international, peer-reviewed, open access, online journal that focuses on the latest clinical and experimental research in all aspects of skin disease and cosmetic interventions. This journal is indexed on CAS.
The manuscript management system is completely online and includes a very quick and fair peer-review system, which is all easy to use. Visit http://www.dovepress.com/testimonials.php to read real quotes from published authors. 